\title{
DÜBLIN
}

Technological University Dublin

ARROW@TU Dublin

2011-01-01

\section{Bioactive Potential and Possible Health Effects of Edible Brown Seaweeds}

\author{
Shilpi Gupta \\ Technological University Dublin, shilpi.19may@gmail.com \\ Nissreen Abu-Ghannam \\ Technological University Dublin, nissreen.abughannam@tudublin.ie
}

Follow this and additional works at: https://arrow.tudublin.ie/schfsehart

Part of the Life Sciences Commons

\section{Recommended Citation \\ Gupta S, Abu-Ghannam N (2011) Bioactive potential and possible health effects of edible brown seaweeds. Trends in Food Science and Technology, 22: 315-326. doi:10.1016/j.tifs.2011.03.011}

This Article is brought to you for free and open access by the School of Food Science and Environmental Health at ARROW@TU Dublin. It has been accepted for inclusion in Articles by an authorized administrator of ARROW@TU

Dublin. For more information, please contact arrow.admin@tudublin.ie, aisling.coyne@tudublin.ie, gerard.connolly@tudublin.ie.

Funder: Irish Government under the Technological Sector Research Scheme (Strand III) of the National Development Plan 
Dublin Institute of Technology

ARROW@DIT

Articles

School of Food Science and Environmental

Health

$1-1-2011$

\section{Bioactive Potential and Possible Health Effects of Edible Brown Seaweeds}

Shilpi Gupta

Nissreen Abu-Ghannam 


\section{Bioactive potential and possible health effects of edible brown seaweeds}

\author{
Shilpi Gupta and \\ Nissreen Abu-Ghannam*
}

School of Food Science and Environmental Health, College of Sciences and Health, Dublin Institute of Technology, Cathal Brugha St., Dublin 1, Ireland.

(Tel.: + 3531402 7570; fax: + 3531402 4411; e-mail: nissreen.abughannam@dit.ie)

Marine macroalgae (seaweeds) are rich in bioactive compounds that could potentially be exploited as functional ingredients for both human and animal health applications. Despite the intensive efforts that are being made to isolate and identify new compounds with potential medicinal, health or pharmaceutical activities, very few compounds with real potency are available. Bioactive compounds that are most extensively researched include sulfated polysaccharides, phlorotannins and diterpenes. These compounds have been reported to possess strong anti-viral, anti-tumor and anti-cancer properties. At the same time, the prebiotic health potential of the polysaccharides from seaweeds is also increasingly being studied either by feeding whole seaweeds or purified polysaccharides to laboratory and farm animals. The present review discusses the pharmaceutical, health and research potential of different bioactive compounds present in brown seaweeds.

\section{Introduction}

Algae are heterogeneous group of plants with a long fossil history. Due to their low content in lipids, high concentration in polysaccharides, natural richness in minerals, polyunsaturated fatty acids and vitamins as well as their content in bioactive molecules, marine algae are known to be a good source of healthy food. Unlike the land plants,

* Corresponding author. these algae have no roots, leaves or vascular systems; however they nourish themselves through the process of osmosis. Two major types of algae that have been identified are the microalgae which are found in both benthic and littoral habitats and also throughout the ocean waters as phytoplankton and the macroalgae or seaweeds which occupy the littoral zone. Seaweeds grow in the intertidal as well as in the sub-tidal area up to a certain depth where very little photosynthetic light is available. Seaweeds are classified into green algae (chlorophyta), brown algae (phaeophyta) and red algae (rhodophyta) on the basis of chemical composition. The color in case of green seaweeds is due to the presence of chlorophyll $a$ and $b$ in the same proportions as the 'higher' plants; beta-carotene (a yellow pigment) and various characteristic xanthophylls (yellowish or brownish pigments). The dominance of the xanthophyll pigment, fucoxanthin, is responsible for the color of brown seaweeds. This compound masks the other pigments such as Chlorophyll $a$ and $c$ and other xanthophylls. Phycoerythrin and phycocyanin mask the pigments such as Chlorophyll $a$ and beta-carotene and are responsible for the color of red seaweeds. Seaweeds are considered as a source of bioactive compounds as they are able to produce a great variety of secondary metabolites characterized by a broad spectrum of biological activities. They are an excellent source of vitamins such as $\mathrm{A}, \mathrm{B}_{1}, \mathrm{~B}_{12}, \mathrm{C}, \mathrm{D}$ and $\mathrm{E}$, riboflavin, niacin, pantothanic acid and folic acid as well as minerals such as Ca, P, Na, K (Dhargalkar \& Pereira, 2005). The fat content of seaweeds accounts for $1-6 \mathrm{~g} / 100 \mathrm{~g}$ dry weight with some brown varieties, such as Hizikia sp. and Arame, having a fat content as low as 0.7-0.9 g/ $100 \mathrm{~g}$ dry weight (Kolb, Vallorani, \& Stocchi, 1999). The red and the green species are rich in carbohydrates whereas the brown seaweeds are rich in soluble fiber and iodine. The highest iodine content is found in brown algae, with dry kelp (Laminaria) ranging from 1500 to 8000 ppm and dry rockweed (Fucus) from 500 to 1000 ppm (www. itmonline.org). Although seaweeds are exposed to the adverse environmental conditions such as light and high oxygen concentrations that lead to the formation of free radicals, and other strong oxidizing agents, they do not have any serious photodynamic damage in vivo. Thus, it can be said that seaweeds are able to generate the necessary compounds to protect themselves from external factors such as pollution, stress and UV radiation. This fact suggests that marine algae, like photosynthesizing plants, 


\begin{tabular}{|ll}
\hline Nomenclature \\
$\mu \mathrm{M}$ & Micro molar \\
d.w. & Dry weight \\
DPHC & diphlorethohydroxycarmalol \\
$\mathrm{EC}_{50}$ & Effective concentration of samples at which \\
& $50 \%$ effect is seen \\
GIT & Gastro intestinal tract \\
HCMV & Human cytomegalovirus \\
HIV & Human immunodeficiency virus \\
HSV & Herpes Simplex Virus \\
IC & Concentration at which $50 \%$ inhibition is \\
& achieved \\
kDa & Kilo Dalton \\
ppm & Parts per million \\
RT & Reverse transcriptase \\
SVHV & Sargassum vulgare high viscosity \\
SVLV & Sargassum vulgare low viscosity \\
UV & Ultra violet \\
VHOC & Volatile halogenated organic compounds
\end{tabular}

have anti-oxidative mechanisms and compounds which act as anti-oxidant agents. At the same time, several species of seaweeds have also been found to produce or contain polysaccharides, glycoproteins or other secondary metabolites Q1 with antimicrobial (Cox et al., 2009; Gupta, Rajauria, \& Abu-Ghannam, 2010a), antitumoral (Koyanagi, Tanigawa, Nakagawa, Soeda, \& Shimeno, 2003; Zubia et al., 2009) or anti-viral activity (Artan et al., 2008; Hemmingson, Falshaw, Furneaux, \& Thompson, 2006; Zhu, Chiu, Ooi, Chan, \& Angjr, 2004; 2003). Among all the three types highest phytochemical content have been reported from brown seaweeds (Seafoodplus, 2008). Thus, this review will mainly focus on the bioactive compounds present in the brown seaweeds. Recent developments in the isolation of compounds and characterization of the types of bioactive compounds from brown seaweeds will also be discussed. Focus is placed on the main classes of compounds that could be of medicinal and pharmaceutical value. The health benefits from the consumption of edible seaweeds and their role in nutrition is also explained.

\section{Important metabolites from seaweeds}

The division Phaeophyta consists of 13 orders according to the classification of Bold and Wynne (1985). However, only three orders namely Laminariales, Fucales and Dictyotales have been extensively researched for their phytochemicals. The most studied species of these orders are Laminaria, Ecklonia, Undaria, Himanthalia and Dictyota. In addition to being rich in polysaccharide, other important categories of metabolites found in brown seaweeds include polyphloroglucinol phenolic compounds (Ahn et al., 2004; Chandini, Ganesan, Suresh, \& Bhaskar, 2008), non-polar,

non-polyphenolic secondary metabolites such as terpenes (Siamopoulou et al., 2004), carotenoids such as fucoxanthin, volatile halogenated organic compounds (VHOCs) (Borchardt et al., 2001) and oxylipins (Kupper et al., 2006; Rorrer et al., 1995). This review will mainly focus on polysaccharides, polyphenolic compounds and terpenes in brown seaweeds.

\section{Polysaccharides}

Polysaccharides are a class of macromolecules which are increasingly gaining attention in the biochemical and medical areas due to their immunomodulatory and anticancer effects. These are present primarily in the cell walls and the composition varies according to season, age, species and geographic location. In addition to acting as a food reserve they also provide strength and flexibility to the plant to withstand wave action and maintain ionic equilibrium in the cell. The regularity of their structures also promotes interaction with external ions and inter-chain hydrogen bonding (e.g., gelation). Brown seaweeds are known to produce different polysaccharides, like alginates, fucoidans, and laminarans. Laminarans and fucoidans are the main water-soluble polysaccharides of brown algae whereas high-molecular mass alginic acids are alkalisoluble polysaccharides.

Cellulose microfibrils in cell wall of brown algae are embedded in an amorphous matrix of acid polysaccharide linked to each other by proteins. Brown algae have two kinds of acid polysaccharides present in the extracellular matrix: sulfated fucans and alginic acid.

Fucans, (Fig. 1a), can be classified into three major groups: fucoidans, xylofucoglycuronans and glycorunogalactofucans. Fucoidan is a branched polysaccharide sulfate ester with L-fucose 4-sulfate building blocks as the major

a

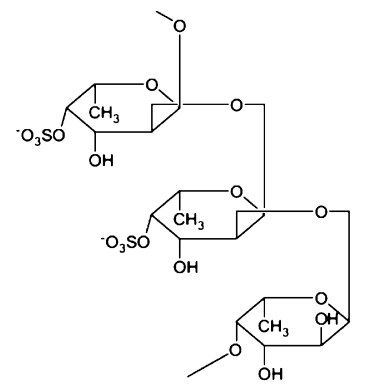

b

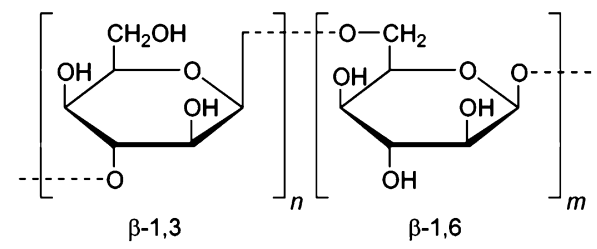

Fig. 1. Structural unit of polysaccharides from brown algae (a) fucoidan; (b) laminaran. 
component. They are predominantly $\alpha(1 \rightarrow 2)$-linked with branching or a sulfate ester group at $\mathrm{C}_{3}$ and is composed of fucose, uronic acids, galactose, xylose and sulfated fucose. The molecular weights reported for fucoidans vary in the range of approximately $100 \mathrm{kDa}$ (Patankar, Oehninger, Barnett, Williams, \& Clark, 1993) to 1600 kDa (Rupérez, Ahrazem, \& Leal, 2002). Fucoidan is soluble in water and in acid solution (Rupérez et al., 2002). Acid hydrolysis of fucoidan yields various amounts of D-xylose, D-galactose, and uronic acid. Algal fucoidans are mainly found in Fucales and Laminariales, but are also present in Chordariales, Dictyotales, Dictyosiphonales, Ectocarpales, and Scytosiphonales. In fact, this kind of sulfated polysaccharide has been discovered in all the brown algae investigated so far, but seems to be absent in green algae, red algae, as well as in freshwater algae and terrestrial plants (Shanmugam \& Mody, 2000). Xylofucoglycuronans or ascophyllans consist of a polyuronide backbone, mainly polyp-(1,4)-D-mannuronic acid branched with 3-O-D-xylosyl-L-fucose-4-sulfate or occasionally uronic acid. Glycuronogalactofucans are composed of linear chains of $(1,4)$-D-galactose branched at $\mathrm{C}_{5}$ with L-fucosyl-3-sulfate or occasionally uronic acid (Jiménez-Escrig \& Sánchez-Muniz, 2000).

Laminaran (or laminarin) was first discovered in Laminaria species and appears to be the food reserve of all brown algae. The major sugar of Laminaria species is laminaran whose structure and composition vary according to algae species. Laminaran is a water-soluble polysaccharide containing 20-25 glucose units which are composed of $(1,3)-\beta$-D-glucan with $\beta(1,6)$ branching (Nelson \& Lewis, 1974) (Fig. 1b). There are two types of laminaran chains (M or $\mathrm{G})$, which differ in their reducing end. $M$ chains end with a mannitol residue whereas $G$ chains end with a glucose residue. Laminaran's molecular weight is approximately $5000 \mathrm{Da}$ depending on the degree of polymerization. Most laminarans form complex structures that are stabilized by inter-chain hydrogen bonds and are therefore resistant to hydrolysis in the upper gastro-intestinal tract (GIT) and are considered as dietary fibers (Neyrinck, Mouson, \& Delzenne, 2007). The structure and the biological activities of laminaran and galactofucan are thought to be influenced by environmental factors, such as water temperature, nutritive salt, salinity, waves, sea current and depth of immersion. In addition to the role of laminarins as prebiotics and dietary fibers they have also been reported to possess antibacterial and anti-tumor activities.

Alginic acid or alginate is the common name given to a family of linear polysaccharides containing 1,4-linked $\beta$-D-mannuronic and $\alpha$-L-guluronic acid (Fig. 2) residues arranged in a non-regular, block wise order along the chain (Andrade et al., 2004). Alginate produced by brown seaweed, especially in the form of sodium and calcium alginate, is widely used in the food and pharmaceutical industries due to their ability to chelate metal ions and to form highly viscous solutions.

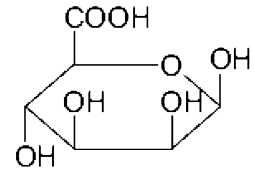

a

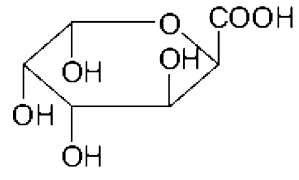

b
Fig. 2. Monomeric compounds present in Alginic acid. (a) $\beta$-D-mannuronic acid; (b) $\alpha$-L-guluronic acid (Davis, Volesky, \& Mucci, 2003).

Sulfated polysaccharides from marine algae have been described as possessing diverse biological activities with potential medicinal value, such as anti-coagulant, anti-tumor, anti-viral and anti-oxidant (Koyanagi et al., 2003; Ponce, Pujol, Damonte, Flores, \& Stoerz, 2003; Shanmugam \& Mody, 2000; Wijesekara, Pangestuti, \& Kim, 2011 (and references therein)).

\section{Other metabolites from seaweeds}

Phlorotanins (Fig. 3) are tannin derivatives which are composed of phloroglucinol-based phenolics (1,3,5-trihydroxybenzene) and are synthesized via the acetatemalonate pathway. They are stored in special vesicals (physodes) and are thought to be the defense compounds in brown seaweeds. The concentration of phlorotannins in brown algae is reported to be highly variable among different taxa of brown seaweeds as well as among different geographical areas. Concentrations are reported to be higher in fucoid species and those obtained from the Atlantic and the temperate Pacific as compared to those obtained from the tropical Pacific (Targett \& Arnold, 1998). Phlorotannins have secondary functions as defensive compounds and primary roles in cell-wall construction (Arnold \& Targett, 2003).

Diterpenes (Fig. 4) are non-volatile halogenated compounds with different carbon structure including xenicane, dolabellane and prenylated guaiane skeletons (Blunt et al., 2009). Brown algae belonging to the genus Dictyota are a rich source of diterpenes. Dictyodial, dictyol C and dictyol $\mathrm{H}$, which are typical algal terpenes previously isolated from different species of Dictyota (Manzo et al., 2009). These secondary metabolites deter feeding by marine herbivores.

Volatile halogenated compounds such as bromophenols are common marine secondary metabolites, arising largely from the propensity of the phenol moiety to undergo electrophilic bromination. Bromophenols have been isolated from taxonomically diverse marine algae, for example, the brown algae Fucus vesiculosus and Leathesia nana (Xu et al., 2004a; 2004b). These compounds have been reported to act as a natural defense mechanism to prevent biofouling on the surface of Laminaria digitata by deactivation of acylated homoserine lactones (Borchardt et al., 2001). The presence of halogen substituent is unique for marine metabolites while it is rare for compounds obtained from terrestrial sources (Venkateswarlu, Panchagnula, Gottumukkala, \& Subbaraju, 2007). The natural function of these compounds in seawater is uncertain, but it is often 
<smiles>Oc1cc(O)cc(O)c1</smiles>

Eckol<smiles>Oc1cc(O)cc(Oc2c(O)cc3c(c2O)Oc2cc(Oc4c(O)cc(O)cc4O)c(O)c(O)c2O3)c1</smiles>

Diphlorethohydroxycarmalol

Fig. 3. Chemical structures of different types of phlorotannins (Heo et al., 2009; 2010). suggested or assumed that they function as antimicrobial compounds or grazing deterrents.

Many marine macroalgae produce oxylipins, some of them belong to the prostaglandin and leukotriene series and share striking similarities with the products of cyclooxygenases and lipo-oxygenases in mammals. These oxylipins have been shown to play a role in chemical attraction and defense mechanisms. The formation of oxylipins in $L_{\lambda}$ digitata was up-regulated in sporophytes challenged with lipopolysaccharides which may function as pathogen-associated molecular patterns (Kupper et al., 2006). Ritter et al. (2008) reported that copper-induced

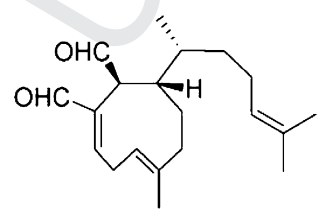

a

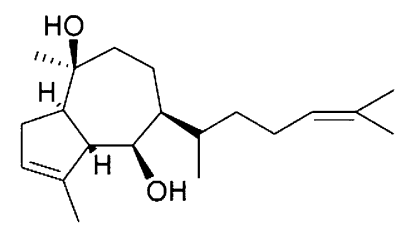

b

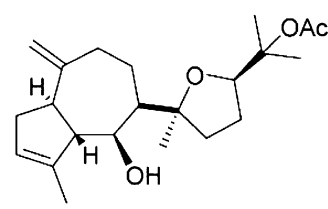

C
Fig. 4. Structure of Diterpenes isolated from brown algae (Manzo et al., 2009) (a) Dictyodial; (b) Dictyol C; (c) Dicytol H. 
stress in L. digitata encouraged the accumulation of a number of complex oxylipins, which were thought to trigger protective mechanisms. Chemical attraction between female and male brown algal gametes is mediated by pheromones, such as hormosirene and fucoserratene, which are hydrocarbons, thought to be down-stream products of a lipo-oxygenase pathway (Pohnert \& Boland, 2002).

Fucoxanthin is the major biofunctional pigment present in brown seaweeds and is one of the most abundant carotenoid found in nature. It has a molecular structure consisting of an unusual allenic bond and a 5,6-monoepoxide. Fucoxanthin has been reported to have anti-oxidant and anti-tumor properties. Recently, it has been claimed that fucoxanthin can help in increasing the metabolism thereby controlling the weight gain in animal models (Maeda, Hosokawa, Sashima, \& Miyashita, 2007). Heo, Yoon et al. (2010) studied the anti-inflammatory effect of fucoxanthin isolated from brown algae via inhibitory effect of nitric oxide production in lipopolysaccharide-induced RAW 264.7 macrophage cells.

Various methods have been used for the extraction and release of the bioactive compounds from seaweeds of which the use of organic solvents is most common. However, focus is now shifting to the use of green technologies such as enzyme assisted extraction (Heo, Park, Lee, \& Jeon, 2005), sub- and super-critical fluid for the extraction (Plaza, Cifuentes, \& Ibañez, 2008 and references therein; Herrero, Cifuentes, \& Ibáñez, 2006 and references therein) of bioactive compounds.
Bioactive properties of compounds from seaweeds

Polysaccharides: anti-tumor, anti-viral, anti-coagulant

Researchers have observed the effect of polysaccharides in biological systems as anti-coagulant, anti-tumor and anti-inflammatory agents (Table 1) and, which has led to the search for new compounds in the last few decades. Generally, the biological activity of polysaccharides from marine algae is related to the molecular size, type of sugar, sulfate content, type of linkage and molecular geometry which are known to have a role in their activities (Zhu et al., 2004). Besides their well attested anti-coagulant and anti-thrombotic activity, they act on the inflammation and immune systems, have anti-proliferative and antiadhesive effect on cells, protect cells from viral infection, and can interfere with mechanisms involved in fertilization.

\section{Anti-tumor property}

Polysaccharides have shown good immunomodulatory properties associated with anti-tumor effects and thus search for these compounds in gaining attention. A role of sulfated polysaccharides from algae as anti-neoplastic agent has been suggested. Several investigations have reported that sulfated polysaccharides have antiproliferative activity in cancer cell lines in vitro, as well as inhibitory activity against tumors growing in mice (de Souza, Torres et al., 2007; de Souza, Marques et al., 2007). Increasing the number of sulfate groups in the fucoi- Q2 dan molecule has been shown to affect the anti-tumor and anti-angiogenic activity (Koyanagi et al., 2003).

\begin{tabular}{|c|c|c|c|c|}
\hline & $\begin{array}{l}\text { Bioactive } \\
\text { compounds }\end{array}$ & $\begin{array}{l}\text { Specific } \\
\text { compound }\end{array}$ & $\begin{array}{l}\text { Possible health } \\
\text { effect }\end{array}$ & References \\
\hline F. evanescens & Fucoidan & & $\begin{array}{l}\text { Anti-tumor and } \\
\text { Anti-metastatic }\end{array}$ & Alekseyenko et al., 2007 \\
\hline F. vesiculosus & Fucan & & $\begin{array}{l}\text { Inhibitor of avian RT; } \\
\text { Antithrombin }\end{array}$ & $\begin{array}{l}\text { Queiroz et al., 2008; } \\
\text { Mourão, } 2004\end{array}$ \\
\hline A. utricularis & Fucoidan & Galactofuran & $\begin{array}{l}\text { Inhibitory against } \\
\text { HSV } 1 \text { and } 2\end{array}$ & Ponce et al., 2003 \\
\hline L. japonica & Laminarin & & Anti-apoptotic & Kim et al., 2006 \\
\hline U. pinnatifida & sulfated polysac. & & Anti-viral & Hemmingson et al., 2006 \\
\hline E. cava & Phlorotannin & Dieckol & Whitening effect & Heo et al., 2009 \\
\hline Eisenia arborea & Phlorotannin & Phlorofucofuroeckol-B & Anti-allergy & Sugiura et al., 2007 \\
\hline I. okamurae & Phlorotannin & diphlorethohydroxycarmalol & $\begin{array}{l}\text { Whitening effect; } \\
\text { Anti-diabetic }\end{array}$ & Heo et al., 2009, 2010 \\
\hline E. cava & Phlorotannin & $\begin{array}{l}\text { 8, } 8^{\prime} \text {-bieckol; 8, } 4^{\prime \prime \prime} \text { dieckol, } \\
6,6^{\prime} \text {-bieckol }\end{array}$ & Inhibitor of HIV-1 RT & $\begin{array}{l}\text { Artan et al., 2008; } \\
\text { Ahn et al., } 2004\end{array}$ \\
\hline E. cava & Phlorotannin & dioxinodehydroeckol & Anti-cancer & Kong et al., 2009 \\
\hline Pelvetia siliquosa & Phlorotannin & fucosterol & Anti-diabetic & Lee et al., 2004 \\
\hline Ecklonia kurome & Phlorotannin & phlorofucofuroeckol A & Algicidal & Nagayama et al., 2003 \\
\hline S. vulgare & $\begin{array}{l}\text { Alginic acid, } \\
\text { xylofucans }\end{array}$ & & Anti-tumor & $\begin{array}{l}\text { de Souza, Marques et al. (2007); } \\
\text { de Souza, Torres et al. } 2007\end{array}$ \\
\hline Dictyota menstrualis & Diterpenes & Da-1; AcDa-1 & Anti-retroviral & Pereira et al., 2004 \\
\hline Dictyota sp. & Diterpene & 4,18-dihydroxydictyolactone & Cytotoxic & Jongaramruong \& Kongkam, 2007 \\
\hline Dictyota pfaffii & Diterpene & 8,10,18-trihydroxy-2,6-dolabelladiene & $\begin{array}{l}\text { Inhibitory against } \\
\text { HSV- } 1 \text {; decrease } \\
\text { the content of } \\
\text { HSV- } 1 \text { early proteins }\end{array}$ & Abrantes et al. (2010) \\
\hline
\end{tabular}


Dias et al. (2008) isolated a polysaccharide called as Sarg from the brown seaweed Sargassum stenophyllum, collected from Santa Catarina State, Brazil. The polysaccharide, Sarg, was studied for its anti-vasculogenic effects both in vivo and in vitro assays, as well as for its capacity to modify embryonic morphogenetic processes endogenously regulated by bFGF, a well-known angiogenic stimulator. Sarg could effectively inhibit vasculogenesis as well as developmental angiogenesis in chick embryos and could trigger concomitantly with vasculogenesis a specific change in the morphogenetic pattern.

Aisa et al. (2005) reported that fucoidan from $F_{\lambda}$ vesiculosus inhibited the proliferation and induced apoptosis in human lymphoma HS-Sultan cell lines. They reported the fucoidan-induced apoptosis through a mitochondrial pathway as the mitochondrial potential in HS-Sultan cells was decreased $24 \mathrm{~h}$ after treatment with fucoidan.

Alekseyenko et al. (2007) studied the anti-tumor and anti-metastatic activities of fucoidan, isolated from Fucus evanescens present in Okhotsk sea, Russia in C57B1/6 mice with transplanted Lewis lung adenocarcinoma. Fucoidan in a dose of $10 \mathrm{mg} / \mathrm{kg}$ and $25 \mathrm{mg} / \mathrm{kg}$ potentiated the anti-metastatic and anti-tumor activities of cyclophosphamide, respectively.

Kim, Kim, Kim, Lee, and Lee (2006) investigated the anti-apoptotic activity of laminaran polysaccharides isolated from the Laminaria japonica. The authors carried out a detailed pharmacological investigation on the laminaran polysaccharides and reported that it suppressed mouse thymocyte apoptosis and at the same time significantly induced the upregulation of 33 immunomodulatory genes from a total of 7410 genes which were examined using a cDNA microarray.

Alginates from brown seaweeds have also been reported to possess anti-tumor activity. de Sousa, Torres et al. (2007); deSouza, Marques et al. (2007) investigated the in vivo anti-tumor activity of two alginates (Sargassum vulgare high viscosity (SVHV) and $S_{\mathrm{\lambda}}$ vulgare low viscosity (SVLV)) with different viscosity extracted from brown seaweed $S_{\mathrm{X}}$ vulgare C Agardh, present in the Atlantic coast of Brazil, against Sarcoma 180 cells transplanted in mice. Both alginates could inhibit the growth of Sarcoma 180. The histopathological analysis of liver and kidney showed that both organs were affected by SVHV and SVLV treatment. However, only SVLV led to acute tubular necrosis. Alginates caused the enlargement of the white pulp of the spleen of treated animals, suggesting that the observed anti-tumor activity could be related to alginates immunomodulatory properties.

\section{Anti-viral property}

The anti-viral polysaccharides should have very low cytotoxicity toward mammalian cells if it is to be used for medicinal purposes and most of the algal polysaccharides have this attribute. Fucoidan has anti-viral properties toward viruses such as HIV and human cytomegalovirus (HCMV).
Ponce et al. (2003) reported the presence of two different types of fucoidans, galactofuran and uronofucoidan, in the seaweeds Adenocystis utricularis collected from the shores near Comodoro Rivadavia, Argentina. The galactofuran showed a high inhibitory activity against herpes simplex virus (HSV) 1 and 2, with no cytotoxicity whereas uronofucoidans had no anti-viral activity. The extraction of a polysaccharides fraction from aqueous extract of Sargassum patens, collected from Hong Kong coastal waters, has also been reported to be highly potent against HSV-1 and $\mathrm{HSV}-2$ with an $\mathrm{EC}_{50}$ value as low as $25 \mu \mathrm{g} / \mathrm{ml}$ and $12.5 \mu \mathrm{g} / \mathrm{ml}$, respectively. The polysaccharide had low levels of cytotoxicity toward mammalian cells (Zhu, Ooi, Chan, \& Ang Jr., 2003). However, the characterization of this fraction has still not been done.

Chen, Lim, Sohn, Choi, and Han (2009) studied the inhibitory effects of fucoidan, isolated from Undaria pinnatifida collected from north east coast of Korea, on the growth of Plasmodium falciparum parasites in vitro and on Plasmodium berghei-infected mice in vivo. Fucoidan significantly inhibited the invasion of erythrocytes by $P$. falciparum merozoites, and its $\mathrm{EC}_{50}$ was found to be similar to those for the chloroquine-sensitive $P$. falciparum 3D7 strain and the chloroquine-resistant K1 strain. Queiroz et al. (2008) assessed the activity of fucans isolated from

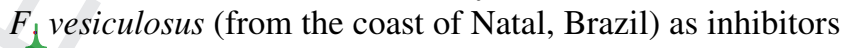
of HIV from reverse transcriptase (RT). These fucans had a pronounced inhibitory effect in vitro on the avian-RT at a concentration of $0.5-1.0 \mu \mathrm{g} / \mathrm{mL}$. The alginic acid $(1.0 \mathrm{mg} / \mathrm{mL})$ inhibited the RT activity by $51.1 \%$ using activated DNA. The authors attributed the inhibitory to the fucans to the presence of sulfate groups as desulphation resulted in the loss of this effect. Furthermore it was suggested that fucan activity was not only dependent on the ionic changes but also on the sugar rings that act to spatially orientate the charges in a configuration that recognizes the enzyme, thus determining the specificity of the binding (Queiroz et al., 2008). Hemmingson et al. (2006) studied the anti-viral activity of a galactofucan sulfate extract from $U$. pinnatifida collected from east coast of Tasmania, Australia. It was found to be a potent inhibitor of the herpes viruses HSV-1, HSV-2 and HCMV, with $\mathrm{IC}_{50}$ values of $1.1,0.2$ and $0.5 \mu \mathrm{g} / \mathrm{mL}$, respectively.

\section{Anti-coagulant property}

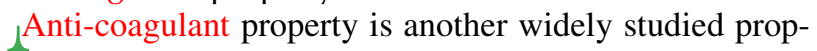
erty of sulfated polysaccharides. Anti-coagulant activity of sulfated polysaccharides has been identified from several brown seaweeds such as Padina gymnospora (Silva et al., 2005), Dictyota menstrualis (Albuquerque et al., 2004) and $F_{\mathrm{X}}$ vesiculosus (Mourão, 2004).

Yoon, Pyun, Hwang, and Mourão (2007) isolated an acidic polysaccharide from Laminaria cichorioides collected from east coast of Korea which was shown to have a potent anti-coagulant activity mainly mediated by thrombin inhibition by heparin cofactor II. Studies using 
a sulfated fucan from $F_{\lambda}$ vesiculosus suggested that the antithrombin activity is mediated mainly by heparin cofactor II, with a minor contribution of antithrombin (Mourão, 2004).

\section{Diterpenes}

Diterpenes have been reported to have cytotoxic, antiviral and algicidal activities (Table 1). Several types of diterpenoids, such as dolabellanes, hydroazulenoids, xenicanes and so-called extended sesquiterpenoids, have been found to be the main secondary metabolites of the species belonging to the Dictyotaceae family.

\section{Anti-tumor property}

Two diterpenes, 4,18-dihydroxydictyolactone 132 and 8a,11 dihydroxypachydictyol A 133, were isolated from a Dictyota sp. collected from Bangsaen Beach, Thailand (Jongaramruong \& Kongkam, 2007). In bioassays, 4,18dihydroxydictyolactone was strongly cytotoxic (NCIH187) (Jongaramruong \& Kongkam, 2007). Awad, Selim, Metawe, and Matloub (2008) isolated 18,19-epoxyxenic19-methoxy-18-hydroxy-4-acetoxy-6,9,13-triene and 18,19epoxyxenic-18,19-dimethoxy-4-hydroxy-6,9,13-triene from methanol extracts of Padina pavonia collected from the Red Sea at Hurghada, Egypt. The isolated compounds showed anti-tumor activities against lung carcinoma (H460) and liver carcinoma (HepG2) human cell lines (in vitro). Zubia et al. (2009) assessed the anti-oxidant and anti-tumoral activities of crude extracts from 10 phaeophyta species from Brittany coasts. ${ }_{\perp}$ Anti-tumoral activities were determined by a cytotoxic assay with three different tumoral cells lines (Daudi, Jurkat and K562). Five species exhibited strong cytotoxic activities against all tumoral cells. The cytotoxic effect was attributed to the high level of diterpenes compounds in the Sargassaceae species used in the study.

\section{Anti-viral property}

Soares et al. (2007) isolated meroditerpenoids atomaric acid, epitaondiol and the peroxylactone of 5'a-desmethyl5 -acetylatomaric acid from Brazilian seaweed Stypopodium zonale. These compounds showed strong anti-HSV-1 activity in vitro but none could inhibit the transcriptase reverse enzyme of HIV-1. Pereira et al. (2004) studied the effect of two diterpenes ((6R)-6-hydroxydichotoma3,14-diene-1,17-dial, named Da-1, and (6R)-6-acetoxidichotoma-3,14-diene-1,17-dial, named AcDa-1) isolated from Brazilian seaweed, Dictyota menstrualis, on HIV-1 replication. The compounds were reported to have an affect on an early step of the virus replicative cycle or during virus adsorption/penetration. The isolated compounds were shown to inhibit the RNA-dependent DNA-polymerase activity of HIV-1 RT in a dose-dependent manner with an $\mathrm{EC}_{50}$ of $40 \mu \mathrm{M}$ and $70 \mu \mathrm{M}$. However, the diterpenes were not as strong as the well-known non-nucleoside inhibitor of the HIV-1 RT nevirapine $\left(\mathrm{EC}_{50} 40 \mathrm{nM}\right)$. Siamopoulou et al. (2004) also reported anti-viral activity of diterpenes isolated from $D$. dichotoma collected from the coasts of Saronikos gulf in Athens and D. linearis from the south coasts of Chios Island. The isolated metabolites did not exhibit significant anti-viral activity against against Poliomyelitis virus I and HSV- 1 in concentrations lower than their maximal non-toxic dose. Abrantes et al. (2010) reported the inhibition of HSV-1 infection in vero cells with diterpenes 8,10,18-trihydroxy-2,6-dolabelladiene and (6-R)-6-hydroxydichotoma-4,14-diene-1,17-dial, isolated from the Brazilian marine algae Dictyota pfaffii and D. menstrualis, respectively. The compounds inhibited HSV-1 replication in a dose-dependent manner, resulting in $\mathrm{EC}_{50}$ values of 5.10 and $5.90 \mu \mathrm{M}$, respectively, for a multiplicity of infection of 5 . In addition, the tested molecules could decrease the contents of some HSV-1 early proteins, such as UL-8, RL-1, UL-12, UL-30 and UL-9.

\section{Phlorotannins}

Phlorotannins have been clarified to exhibit anti-diabetic (Lee, Shin, Kim, \& Lee, 2004), anti-oxidation (Ahn et al., 2007), anti-cancer (Kong, Kim, Yoon, \& Kim, 2009; Yang, Zeng, Dong, Liu, \& Li, 2010), and anti-HIV (Ahn et al., 2004) (Table 1) activities.

\section{Anti-oxidant property}

Heo, Ko et al. (2009) isolated three kinds of phlorotannins from Ecklonia cava collected from the coast of Jeju Island, Korea and studied their inhibitory effect on melanogenesis as well as their protective effect against photooxidative stress induced by UV-B radiation. They reported that the phlorotannin, dieckol, has potential whitening effects and prominent protective effects on UV-B radiation-induced cell damages. Dieckol showed $88.9 \%$ tyrosinase inhibitory activity even at $50 \mu \mathrm{M}$, and the values were higher than that of commercial whitening agent, kojic acid. Heo, Ko et al. (2010) also isolated diphlorethohydroxycarmalol (DPHC) from Ishige okamurae extracts. DPHC demonstrated strong protective properties against UV-B radiation via damaged DNA tail length and morphological changes in fibroblast, thus showing that the compound has a potential whitening effect and can have potential use in the pharmaceutical and cosmetic industry.

\section{Anti-allergic property}

The anti-allergic properties of several phlorotannins isolated from seaweeds have been studied on leukemia cell lines in vitro. Sugiura et al. (2007) isolated a phlorotannin, phlorofucofuroeckol-B, from Eisenia arborea collected from the Mugizaki coast in Mie prefecture, Japan. The compound was reported to have anti-allergic properties. The isolation was guided by the inhibitory effect of the collected fractions from the extract on histamine release $\left(\mathrm{IC}_{50}\right.$ $7.8 \mu \mathrm{M}$ ) from rat basophile leukemia (RBL-2H3) cells in a concentration-dependent manner. Le, Li, Qian, Kim, and Kim (2009) isolated two main bioactive phlorotannin 
derivatives together with phloroglucinol and dieckol having anti-allergy activity from crude extracts of Korean seaweed Ecklonia cava. The anti-allergic activity of these derivatives was assessed by histamine release assay on human basophilic leukemia (KU812) and rat basophilic leukemia (RBL-2H3) cultured cell lines, respectively. Strong inhibitory effect was shown by dieckol and one phlorotannin derivative.

\section{Anti-diabetic property}

In vivo testing of fucosterol in streptozotocin-induced diabetic rats, isolated from the brown alga Pelvetia siliquosa, demonstrated that it is the main anti-diabetic principle (Lee et al., 2004). Fucosterol caused a significant decrease in serum glucose concentrations, and exhibited an inhibition of sorbitol accumulations in the lenses of rats (Lee et al., 2004). Heo, Hwang et al. (2009) reported that diphlorethohydroxycarmalol (DPHC) isolated from $I_{\lambda}$ okamurae collected along the Coast of Jeju Island, Korea might be a potent inhibitor of $\alpha$-glucosidase and $\alpha$-amylase. The $\mathrm{IC}_{50}$ values of DPHC against $\alpha$-glucosidase and $\alpha$-amylase were 0.16 and $0.53 \mathrm{mM}$, respectively, which evidenced the higher activities than that of acarbose. Moreover, DPHC did not seem to exert any cytotoxic effect in human umbilical vein endothelial cells at various concentrations (from 0.49 to $3.91 \mathrm{mM}$ ). At the same time, the increase of postprandial blood glucose levels were significantly suppressed in the DPHC-administered group than those in the streptozotocin-induced diabetic or normal mice.

\section{Anti-viral property}

Tannins have been reported to show their HIV-1 inhibitory mode of action by inhibiting polymerase and ribonuclease activities of HIV-1 RT (Artan et al., 2008). Ahn et al. (2004) isolated four phlorotannin derivatives, eckol (1), 8,8'-bieckol (2), 8,4'"dieckol (3), and phlorofucofuroeckol A (4) from $E_{\mathrm{\lambda}}$ cava. Among these, compounds

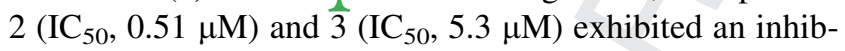
itory effect on HIV-1 RT. Both these compounds were able to inhibit the protease as well but RT was inhibited more potently than the protease. Another phlorotannin 6,6'bieckol was isolated from $E_{\Lambda}$ cava and studied for its antiviral properties (Artan et al., 2008). The compound showed wild inhibition against HIV-1 induced syncytia formation $\left(\mathrm{EC}_{50} 1.72 \mu \mathrm{M}\right)$, lytic effects $\left(\mathrm{EC}_{50} 1.23 \mu \mathrm{M}\right)$, and viral p24 antigen production $\left(\mathrm{EC}_{50} 1.26 \mu \mathrm{M}\right)$, respectively in addition to inhibiting the activity of HIV-1 RT enzyme with $\mathrm{EC}_{50}$ of $1.07 \mu \mathrm{M}$, as well as HIV-1 entry.

\section{Anti-tumor property}

Kong et al. (2009) isolated phloroglucinol derivatives, dioxinodehydroeckol (1) and 1-(3',5'-dihydroxyphenoxy)7-(2", $4^{\prime \prime}, 6$-trihydroxyphenoxy)-2,4,9-trihydroxydibenzo-1, 4-dioxin (2), from $E_{\Lambda}$ cava and checked their ability to inhibit the proliferation of human breast cancer cells. Compound 1 exerted a higher anti-proliferative activity in human breast cancer cells, induced a significant proliferative inhibition and apoptosis in a dose-dependent manner on MCF-7 human cancer cells and also induced the increase in caspase ( -3 and -9$)$ activity. Yang et al. (2010) studied the anti-proliferative activity of phlorotannins derived from brown algae $L_{\Lambda}$ japonica Aresch extracts collected from Quingdao, China on the human hepatocellular carcinoma cell (BEL-7402) and on murine leukemic cells (P388) by MTT assay. The inhibitory rate of phlorotannin extract on BEL-7402 and P388 cells was $30.20 \pm 1.16 \%$ and $43.44 \pm 1.86 \%$, respectively, and $\mathrm{IC}_{50}$ on P388 and BEL-7402 cells was $120 \mu \mathrm{g} / \mathrm{mL}$ and $>200 \mu \mathrm{g} / \mathrm{mL}$, respectively.

\section{Antibacterial and algicidal property}

In addition, bactericidal (Nagayama, Iwamura, Shibata, Hirayama, \& Nakamura, 2002) and algicidal activity (Nagayama, Shibata, Fujimoto, Honjo, \& Nakamura, 2003; Wang, Xiao, Wang, Zhou, \& Tang, 2007) of phlorotannins has also been reported. Nagayama et al. (2003) reported phlorofucofuroeckol $\mathrm{A}$, to have algicidal activity as strong as that of epigallocatechin gallate. Nagayama et al. (2002) found the bactericidal effect of the phlorotannins to be more pronounced than those of the catechins which was used as positive control. Wang, Xu, Bach, and MacAllister (2009) reported the bactericidal effects of phlorotannins isolated from Ascophyllum nodosum collected from Atlantic coastline of Nova Scotia, Canada against E. coli O157:H7. The marine phlorotannis were reported to be superior in activity as compared to terrestrial phlorotannins.

While all these studies show substantial evidence to suggest that seaweed phytochemicals have the potential to be used as nutraceuticals or in pharmaceutical industry, to date not much progress has been made on in vivo activity of these compounds isolated from seaweeds.

\section{Health benefit due to consumption of seaweed dietary fibers}

Being rich in polysaccharides which are not digested by intestinal enzymes makes seaweeds an important source of dietary fibers and can be considered as a source of prebiotics. A prebiotic is a compound which must be resistant to digestion in the upper GIT and therefore resistant to acid and enzymatic hydrolysis; must be a selective substrate for the growth of beneficial bacteria and finally, it must induce luminal or systemic effects that are beneficial to host health. These dietary fibers differ chemically and physico-chemically from that of the terrestrial species and may induce different fermentative patterns. The content of total dietary fiber in seaweeds ranges from 33 to $50 \mathrm{~g} /$ 100 g d.w. (Rupérez \& Saura-Calixto, 2001). Accordingly, the fiber content of seaweed varieties is higher than those found in most fruits and vegetables. The human consumption of algal fiber has been proven to be health-promoting and its benefits are well documented in the scientific 
literature. The consumption of this dietary fiber has been related to the following health-promoting effects: (1) promotes the growth and protection of the beneficial intestinal flora, (2) reduces the overall glycemic response, (3) greatly increases stool volume and (4) reduces the risk of colon cancer. In addition to the presence of some of the components which have potential benefits for the human body, the presence of dietary fibers provides some technological advantages for the use of marine algae as ingredients in food products such as meat products. The presence of these prebiotics can also be used to support the growth of lactic acid bacteria using seaweed broth as a sole source of nutrition (Gupta, Abu-Ghannam, \& Scannell, 2010b) and subsequently probiotics that can benefit human health. Thus, seaweeds have the potential to be used as a functional food ingredient or as a nutraceutical.

The capacity of the fibers to absorb and retain water (Rupérez \& Saura-Calixto, 2001) helps in the utilization of seaweeds as texturing and bulking agents, particularly in the making of low calorie foods. At the same time, the high concentration of mineral elements in seaweeds can help to reduce the amount of added sodium chloride in meat processing. López-López et al. (2009) studied the influence of the addition of edible seaweeds Himanthalia elongata, $U_{\mathbf{\Lambda}}$ pinnatifida and Porphyra umbilicalis collected from the Atlantic coast, on fatty acid composition, amino acid profile, protein score, mineral content and antioxidant capacity in low-salt meat emulsion model systems. Meat systems made with added seaweeds had lower $(P<0.05)$ sodium contents than control samples. The inclusion of $H$. elongata increased the sulfur amino acid score by $20 \%$. The added seaweeds supplied the meat samples with soluble polyphenolic compounds, which increased the anti-oxidant capacity of the systems.

The prebiotic effect of seaweed polysaccharide was shown by its ability to resist digestion in the upper GIT in a study conducted by Deville, Damas, Forget, Dandrifosse, and Peulen (2004). They reported that laminarin remained intact following incubation in vitro with hydrochloric acid, human saliva and human gastric, pancreatic, small intestinal and colonic homogenates. Feeding trials have also been performed in laboratory animals to investigate the effects on animal health and growth performance. Guidel-Urbano and Goñi (2002) studied the influence of feeding two edible seaweeds, Porphyra and Undaria purchased from a local health store in Madrid, Spain, as a source of dietary fiber on dietary nutritive utilization in male adult Wistar rats. The addition of seaweed did not affect the gain in body weight of rats or food efficiency but the fresh and dry stool weights were higher in rats fed seaweeds than in the control group. Seaweed-fed animals showed significantly lower apparent digestibilities of protein and fat but absorbed nitrogen was more effectively used by animals. Evidence is also available on the prebiotic effect of seaweed polysaccharide on animal health. Kuda, Yano, Matsuda, and Nishizawa (2005) reported that dietary supplementation with $1 \%$ laminarin resulted in an increase in Bifidobacterium counts in the cecum of rats compared to a control diet, but there was no significant difference in Lactobacillus counts. Wang, $\mathrm{Han}, \mathrm{Hu}, \mathrm{Li}$, and $\mathrm{Yu}$ (2006) reported a selective increase in the numbers of Bifidobacterium and Lactobacillus in both the cecum and faeces of rats which were fed diets supplemented with $2.5 \%$ alginate. The prebiotic effect was found to be greater than the control group which was fed on a diet containing prebiotic fructo-oligosaccharide. Deville, Gharbi, Dandrifosse, and Peulen (2007) noted that laminarin can influence the adherence and the translocation of bacteria across the epithelial wall and seems to be a modulator of the intestinal metabolism by its effects on mucus composition, intestinal $\mathrm{pH}$ and short-chain fatty acid production, especially butyrate. Neyrinck et al. (2007) demonstrated that dietary supplementation with laminarin protected against lipopolysaccharide-induced liver toxicity in a rodent model of systemic inflammation. They suggested that the immunomodulatory effects of dietary laminarin could be either due to a direct effect of laminarin on immune cells or due to an indirect effect via modulation of the intestinal microbiota. Maeda et al. (2007) studied the anti-diabetic and anti-obedisty effect of dietary fucoxanthin and fish oil. They reported that dietary fucoxanthin decreases the blood glucose and plasma insulin concentration of $\mathrm{KK}-A^{y}$ along with down-regulating tumor necrosis factor- $\alpha$ mRNA. Reports are also available on the effect of feeding of farm animals with whole seaweeds or seaweed polysaccharide. Lynch, Sweeney, Callan, O'Sullivan, and O'Doherty (2010) showed the prebiotic effect of feeding pigs with laminaran and fuciodan on interstinal fermentation and selected microflora. Feeding resulted in a reduction in intestinal Enterobacteria and an increase in Lactobacilli sp thus suggesting that feeding of seaweeds can act as a dietary means to improve gut health in pigs. Reilly et al. (2008) demonstrated the effect of dietary supplementation with extracts containing laminarin and fucoidan from different varieties of brown seaweeds, $L_{\mathrm{\Lambda}}$ digitata and Laminaria hyperborea collected from Kerry, Ireland on gut morphology and intestinal microbial populations in pigs. The inclusion resulted in an inhibitory effect on the Enterobacteria, Lactobacilli and Bifidobacteria population within the caecum and colon of weaned pigs. O'Doherty, McDonnell, and Figat (2010) showed that feeding laminarin resulted in the reduction in faecal $E$. coli population and an increase in daily gain and gain to feed ratio to improve gut health in post weaning pigs. However, a combination of laminarin and fucoidan was reported to be more effective at reducing diarrhea post weaning. Dillon, Sweeney, Callan, and O'Doherty (2010) have also reported that the inclusion of a combination of laminarin and fucoidan extract derived from $L_{\mathrm{\lambda}}$ digitata, increased daily gain and gain to feed ratio of post weaned piglets. According to the authors this was mainly due to an increase in nutrient digestibility and decreased $E$. coli populations in 
the guts. Dierick, Ovyn, and De Smet (2010) studied the effect of feeding intact $A_{\alpha}$ nodosum collected from Ireland on the piglet gut flora $(E$. coli, lactobacilli, streptococci, total anaerobic count) and their metabolism. In vitro investigations, simulating in vivo conditions, revealed a statistically significant depressive effect of seaweed on piglet small intestinal and hindgut flora, especially on E. coli. Also the fermentative activity (lactic acid, volatile fatty acids) of the flora was lowered.

\section{Conclusions}

Seaweeds grow in abundance in coastal areas and are available all year round. This review attempted to examine the reports available on the compounds being isolated from seaweeds that may have anti-cancer, anti-tumor or antiviral activity. Many reports have been published about isolated compounds from algae with biological activity, demonstrating their ability to produce metabolites however a lot of research is needed before this vast untapped resource could be utilized for beneficial purposes. Thus, the investigation of new algal chemical compounds, a different source of natural products, can prove to be a promising area of pharmaceutical study. Moreover, substantial amount of research regarding the toxicity aspects also needs to be carried out before they could actually be used for clinical trials. The information available on the prebiotic potential of seaweeds being fed to farm animals seems promising. However, the results from different studies are conflicting and more studies are needed in order to reach a consensus regarding their beneficial dietary effect. At the same time, they may also be a source of compounds which could be exploited for novel functional ingredients for human and animal health applications. Future work in the area of seaweed-derived bioactives should aim to examine the effects of purified compounds under in vivo conditions to understand their actual potential.

\section{Q4 Uncited reference}

Dharmananda.

\section{Acknowledgment}

The authors would like to acknowledge funding from the Irish Government under the Technological Sector Research Scheme (Strand III) of the National Development Plan.

\section{References}

Abrantes, J. L., Barbosa, J., Cavalcanti, D., Pereira, R. C., Fontes, C. F. L., Teixeira, V. L., et al. (2010). The effects of the diterpenes isolated from the Brazilian brown algae Dictyota pfaffii and Dictyota menstrualis against the herpes simplex type-1 replicative cycle. Planta Medica, 76, 339-344.

Ahn, M. J., Yoon, K. D., Min, S. Y., Lee, J. S., Kim, J. H., Kim, T. G., et al. (2004). Inhibition of HIV-1 reverse transcriptase and protease by phlorotannins from the brown alga Ecklonia cava. Biological and Pharmaceutical Bulletin, 27, 544-547.

Ahn, G. N., Kim, K. N., Cha, S. H., Song, C. B., Lee, J. H., Heo, M. S., et al. (2007). Antioxidant activities of phlorotannins purified from
Ecklonia cava on free radical scavenging using ESR and $\mathrm{H}_{2} \mathrm{O}_{2-}$ mediated DNA damage. Journal of European Food Research and Technology, 226, 71-79.

Aisa, Y., Miyakawa, Y., Nakazato, T., Shibata, H., Saito, K., Ikeda, Y., \& Kizaki, M. (2005). Fucoidan induces apoptosis of human HS-sultan cells accompanied by activation of caspase- 3 and down-regulation of ERK pathways. American Journal of Hematology, 78, 7-14.

Albuquerque, I. R. L., Queiroz, K. C. S., Alves, L. G., Santos, E. A., Leite, E. L., \& Rocha, H. A. O. (2004). Hetarofucans from Dictyota menstrualis have anticoagulant activity. Brazilian Journal of Medical and Biological Research, 37, 167-171.

Alekseyenko, T. V., Zhanayeva, S. Y., Venediktova, A. A., Zvyagintseva, T. N., Kuznetsova, T. A., Besednova, N. N., \& Korolenko, T. A. (2007). Antitumor and antimetastatic activity of fucoidan, a sulfated polysaccharide isolated from the Okhotsk sea Fucus evanescens brown alga. Bulletin of Experimental Biology and Medicine, 143, 730-732.

Andrade, L. R., Salgado, L. T., Farina, M., Pereira, M. S., Mourão, P. A. S., \& Amado-Filho, G. M. (2004). Ultrastructure of acidic polysaccharides from the cell walls of brown algae. Journal of Structural Biology, 145, 216-225.

Arnold, T. M., \& Targett, N. M. (2003). To grow and defend: lack of trade-offs for brown algal phlorotannins. Oikos, 100, 406-408.

Artan, M., Li, Y., Karadeniz, F., Lee, S. H., Kim, M. M., \& Kim, S. K. (2008). Anti-HIV-1 activity of phloroglucinol derivative, 6,6'-bieckol, from Ecklonia cava. Bioorganic and Medicinal Chemistry, 16, 7921-7926.

Awad, N. E., Selim, M. A., Metawe, H. M., \& Matloub, A. A. (2008). Cytotoxic xenicane diterpenes from the brown alga Padina pavonia (L.) Gaill. Phytotherapy Research, 22, 1610-1613.

Blunt, J. W., Copp, B. R., Hu, W.-P., Munro, M. H. G., Northcote, P. T., \& Prinsep, M. R. (2009). Marine natural products. Natural Products Reports, 26, 170-244.

Bold, H. C., \& Wynne, M. J. (1985). Introduction to the algae. Englewood Cliffs, NJ: Prentice-Hall. 516.

Borchardt, S. A., Allain, E. J., Michels, J. J., Stearns, G. W., Kelly, R. F., \& Mccoy, W. F. (2001). Reaction of acylated homoserine lactone bacterial signaling molecules with oxidized halogen antimicrobials. Applied and Environmental Microbiology, 67, 3174-3179.

Chen, J. H., Lim, J. D., Sohn, E. H., Choi, Y. S., \& Han, E. T. (2009). Growth-inhibitory effect of a fucoidan from brown seaweed Undaria pinnatifida on Plasmodium parasites. Parasitology Research, 104, 245-250.

Cox, S., Abu-Ghannam, N., \& Gupta, S. (2009). An assessment of the antioxidant and antimicrobial activity of six species of edible Irish seaweeds. International Food Research Journal, 17, 205-220.

Davis, T. A., Volesky, B., \& Mucci, M. (2003). A review of the biochemistry of heavy metal biosorption by brown algae. Water Research, 37, 4311-4330.

Deville, C., Damas, J., Forget, P., Dandrifosse, G., \& Peulen, O. (2004). Laminarin in the dietary fiber concept. Journal of the Science of Food and Agriculture, 84, 1030-1038.

Deville, C., Gharbi, M., Dandrifosse, G., \& Peulen, O. (2007). Study on the effects of laminarin, a polysaccharide from seaweed, on gut characteristics. Journal of the Science of Food and Agriculture, 87, 1717-1725.

Dhargalkar, V. K., \& Pereira, N. (2005). Seaweed: promising plant of the millennium. Science and Culture, 71, 60-66.

Dharmananda, S. The nutritional and medicinal value of seaweeds used in Chinese medicine. www.itmonline.org/arts/seaweed.htm. Q3

Dias, P. F., Siqueira Jr., J. M., Maraschin, M., Ferreira, A. G., Gagliardi, A. R., \& Ribeiro-do-Valle, R. M. (2008). A polysaccharide isolated from the brown seaweed Sargassum stenophyllum exerts antivasculogenic effects evidenced by modified morphogenesis. Microvascular Research, 75, 34-44.

Dierick, N., Ovyn, A., \& De Smet, S. (2010). In vitro assessment of the effect of intact marine brown macro-algae Ascophyllum nodosum on the gut flora of piglets. Livestock Science, 133, 154-156. 
Dillon, S., Sweeney, T., Callan, J. J., \& O'Doherty, J. V. (2010). The effects of lactose inclusion and seaweed extract on performance, nutrient digestibility and microbial populations in newly weaned piglets. Animal Feed Science and Technology, 157, 173-180.

Guidel-Urbano, M., \& Goñi, I. (2002). Bioavailability of nutrients in rats fed on edible seaweeds, Nori (Porphyra tenera) and Wakame (Undaria pinnatifida), as a source of dietary fibre. Food Chemistry, 76, 281-286.

Gupta, S., Rajauria, G., \& Abu-Ghannam, N. (2010a). Study of the microbial diversity and antimicrobial properties of Irish edible brown seaweeds. International Journal of Food Science and Technology, 45, 482-489.

Gupta, S., Abu-Ghannam, N., \& Scannell, A. G. M. (2010b). Growth and kinetics of Lactobacillus plantarum in the fermentation of edible Irish brown seaweeds. Food and Bioproducts Processing. doi:10.1016/j.fbp.2010.10.001

Hemmingson, J. A., Falshaw, R., Furneaux, R. H., \& Thompson, K. (2006). Structure and antiviral activity of the galactofucan sulfates extracted from Undaria pinnatifida (Phaeophyta). Journal of Applied Phycology, 18, 185-193.

Heo, S. J., Hwang, J. Y., Choi, J. I., Han, J. S., Kim, H. J., \& Jeon, Y. J. (2009). Diphlorethohydroxycarmalol isolated from Ishige okamurae, a brown algae, a potent $\alpha$-glucosidase and $\alpha$-amylase inhibitor, alleviates postprandial hyperglycemia in diabetic mice. European Journal of Pharmacology, 615, 252-256.

Heo, S. J., Ko, S. C., Cha, S. H., Kang, D. H., Park, H. S., Choi, Y. U., et al. (2009). Effect of phlorotannins isolated from Ecklonia cava on melanogenesis and their protective effect against photooxidative stress induced by UV-B radiation. Toxicology in Vitro, 23, 1123-1130.

Heo, S. J., Ko, S. C., Kang, S. M., Cha, S. H., Lee, S. H., Kang, D. H., et al. (2010). Inhibitory effect of diphlorethohydroxycarmalol on melanogenesis and its protective effect against UV-B radiationinduced cell damage. Food and Chemical Toxicology, 48, 1355-1361.

Heo, S. J., Park, E. J., Lee, K. W., \& Jeon, Y. J. (2005). Antioxidant activities of enzymatic extracts from brown seaweeds. Bioresource Technology, 96, 1616-1623.

Heo, S. J., Yoon, W. J., Kim, K. N., Ahn, G. N., Kang, S. M., Kang, D. H., et al. (2010). Evaluation of anti-inflammatory effect of fucoxanthin isolated from brown algae in lipopolysaccharidestimulated RAW 264.7 macrophages. Food and Chemical Toxicology, 48, 2045-2051.

Herrero, M., Cifuentes, A., \& Ibáñez, E. (2006). Sub- and supercritical fluid extraction of functional ingredients from different natural sources: plants, food-by-products, algae and microalgae: a review. Food Chemistry, 98, 136-148.

Jiménez-Escrig, A., \& Sánchez-Muniz, F. J. (2000). Dietary fibre from edible Seaweeds: chemical structure, physicochemical properties and effects on cholesterol metabolism. Nutrition Research, 20, 585-598.

Jongaramruong, J., \& Kongkam, N. (2007). Novel diterpenes with cytotoxic, anti-malarial and anti-tuberculosis activities from a brown alga Dictyota sp. Journal of Asian Natural Products Research, 9, 743-751.

Kim, K. H., Kim, Y. W., Kim, H. B., Lee, B. J., \& Lee, D. S. (2006). Antiapoptotic activity of laminarin polysaccharides and their enzymatically hydrolyzed oligosaccharides from Laminaria japonica. Biotechnology Letters, 28, 439-446.

Kolb, N., Vallorani, L., \& Stocchi, V. (1999). Chemical composition and evaluation of protein quality by amino acid score method of edible brown marine algae Arame (Eisenia bicyclis) and Hijiki (Hijikia fusiforme). Acta Alimentaria, 28, 213-222.

Kong, C. S., Kim, J. A., Yoon, N. Y., \& Kim, S. K. (2009). Induction of apoptosis by phloroglucinol derivative from Ecklonia Cava in MCF7 human breast cancer cells. Food and Chemical Toxicology, 47, $1653-1658$.
Koyanagi, S., Tanigawa, N., Nakagawa, H., Soeda, S., \& Shimeno, H. (2003). Oversulfation of fucoidan enhances its anti-angiogenic and antitumor activities. Biochemical Pharamacology, 65, 173-179.

Kuda, T., Yano, T., Matsuda, N., \& Nishizawa, M. (2005). Inhibitory effects of laminaran and low molecular alginate against the putrefactive compounds produced by intestinal microflora in vitro and in rats. Food Chemistry, 91, 745-749.

Chandini, S. K., Ganesan, P., Suresh, P. V., \& Bhaskar, N. (2008). Seaweeds as a source of nutritionally beneficial compounds a review. Journal of Food Science and Technology, 45, 1-13.

Kupper, F. C., Gaquerel, E., Boneberg, E. M., Morath, S., Salaun, J. P., \& Potin, P. (2006). Early events in the perception of lipopolysaccharides in the brown alga Laminaria digitata include an oxidative burst and activation of fatty acid oxidation cascades. Journal of Experimental Botany, 57, 1991-1999.

Le, Q. T., Li, Y., Qian, Z. J., Kim, M. M., \& Kim, S. K. (2009). Inhibitory effects of polyphenols isolated from marine alga Ecklonia cava on histamine release. Process Biochemistry, 44, 168-176.

Lee, Y. S., Shin, K. H., Kim, B. K., \& Lee, S. (2004). Anti-diabetic activities of fucosterol from Pelvetia siliquosa. Archives of Pharmacal Research, 27, 1120-1122.

López-López, I., Bastida, S., Ruiz-Capillas, C., Bravo, L., Larrea, M. T., Sánchez-Muniz, F., et al. (2009). Composition and antioxidant capacity of low-salt meat emulsion model systems containing edible seaweeds. Meat Science, 83, 492-498.

Lynch, M. B., Sweeney, T., Callan, J. J., O'Sullivan, J. T., \& O'Doherty, J. V. (2010). The effect of dietary Laminaria derived laminarin and fucoidan on intestinal microflora and volatile fatty acid concentration in pigs. Livestock Science, 133, 157-160.

Maeda, H., Hosokawa, M., Sashima, T., \& Miyashita, K. (2007). Dietary combination of fucoxanthin and fish oil attenuates the weight gain of white adipose tissue and decreases blood glucose in obese/ diabetic KK- $A^{y}$ mice. Journal of Agricultural and Food Chemistry, 55, 7701-7706.

Manzo, E., Ciavatta, M. L., Bakkas, S., Villani, G., Varcamonti, M., Zanfardino, A., \& Gavagnin, M. (2009). Diterpene content of the alga Dictyota ciliolata from a Moroccan lagoon. Phytochemistry Letters, 2, 211-215.

Mourão, P. A. S. (2004). Use of sulfated fucans as anticoagulant and antithrombotic agents: future perspectives. Current Pharmaceutical Design, 10, 967-981.

Nagayama, K., Iwamura, Y., Shibata, T., Hirayama, I., \& Nakamura, T. (2002). Bactericidal activity of phlorotannins from the brown alga Ecklonia kurome. Journal of Antimicrobial Chemotherapy, 50, 889-893.

Nagayama, K., Shibata, T., Fujimoto, K., Honjo, T., \& Nakamura, T. (2003). Algicidal effect of phlorotannins from the brown alga Ecklonia kurome on red tide microalgae. Aquaculture, 218, 601-611.

Nelson, T. E., \& Lewis, B. A. (1974). Separation and characterization of the soluble and insoluble components of insoluble laminaran. Carbohydrate Research, 33, 63-74.

Neyrinck, A. M., Mouson, A., \& Delzenne, N. M. (2007). Dietary supplementation with laminarin, a fermentable marine $\beta(1-3)$ glucan, protects against hepatotoxicity induced by LPS in rat by modulating immune response in the hepatic tissue. International Immunopharmacology, 7, 1497-1506.

O'Doherty, J. V., McDonnell, P., \& Figat, S. (2010). The effect of dietary laminarin and fucoidan in the diet of the weanling piglet on performance and selected faecal microbial populations. Livestock Science, 134, 208-210.

Patankar, M. S., Oehninger, S., Barnett, T., Williams, R. L., \& Clark, G. F. (1993). A revised structure for fucoidan may explain some of its biological activities. The Journal of Biological Chemistry, 268, 21770-21776.

Pereira, H. S., Leão-Ferreira, L. R., Moussatché, N., Teixeira, V. L., Cavalcanti, D. N., Costa, L. J., et al. (2004). Antiviral activity of 
diterpenes isolated from the Brazilian marine alga Dictyota menstrualis against human immunodeficiency virus type 1 (HIV-1). Antiviral Research, 64, 69-76.

Plaza, M., Cifuentes, A., \& Ibañez, E. (2008). In the search of new functional food ingredients from algae. Trends in Food Science and Technology, 19, 31-39.

Pohnert, G., \& Boland, W. (2002). The oxylipin chemistry of attraction and defense in brown algae and diatoms. Natural Products Reports, 19, 108-122.

Ponce, N. M. A., Pujol, C. A., Damonte, E. B., Flores, M. L., \& Stoerz, C. A. (2003). Fucoidans from the brown seaweed Adenocystis utricularis: extraction methods, antiviral activity and structural studies. Carbohydrate Research, 338, 153-165.

Queiroz, K. C. S., Medeiros, V. P., Queiroz, L. S., Abreu, L. R. D., Rocha, H. A. O., Ferreira, C. V., et al. (2008). Inhibition of reverse transcriptase activity of HIV by polysaccharides of brown algae. Biomedicine \& Pharmacotherapy, 62, 303-307.

Reilly, P., Sweeney, T., Pierce, K. M., Callan, J. J., Julka, A., \& O'Doherty, J. V. (2008). The effect of seaweed extract inclusion on gut health and immune status of the weaned pig. Animal, 2, 1465-1473.

Ritter, A., Goulitquer, S., Salaun, J. P., Tonon, T., Correa, J. A., \& Potin, P. (2008). Copper stress induces biosynthesis of octadecanoid and eicosanoid oxygenated derivatives in the brown algal kelp Laminaria digitata. The New Phytologist, 180, 809-821.

Rorrer, G. L., Modrell, J., Zhi, C., Yoo, H.-D., Nagle, D. N., \& Gerwick, W. H. (1995). Bioreactor seaweed cell culture for production of bioactive oxylipins. Journal of Applied Phycology, 7, 187-198.

Rupérez, P., \& Saura-Calixto, F. (2001). Dietary fibre and physicochemical properties of edible Spanish seaweeds. European Food Research and Technology, 212, 349-354.

Rupérez, P., Ahrazem, O., \& Leal, J. A. (2002). Potential antioxidant capacity of sulphated polysaccharides from edible brown seaweed Fucus vesiculosus. Journal of Agricultural and Food Chemistry, 50, $840-845$

Seafoodplus (2008). www.seafoodplus.org/fileadmin/files/news/200401-22SFRTD1 launchBrussels.pdf. Accessed 25.03.10.

Shanmugam, M., \& Mody, K. H. (2000). Heparinoid-active sulphated polysaccharides from marine algae as potential blood anticoagulant agents. Current Science, 79, 1672-1683.

Siamopoulou, P., Bimplakis, A., Iliopoulou, D., Vagias, C., Cos, P., Berghe, D. V., \& Roussis, V. (2004). Diterpenes from the brown algae Dictyota dichotoma and Dictyota linearis. Phytochemistry, 65, 2025-2030.

Silva, T. M. A., Alves, L. G., de Queiroz, K. C. S., Santos, M. G. L., Marques, C. T., Chavante, S. F., et al. (2005). Partial characterization and anticoagulant activity of a heterofucan from the brown seaweed Padina gymnospora. Brazilian Journal of Medical and Biological Research, 38, 523-533.

Soares, A. R., Abrantes, J. L., Souza, T. M. L., Fontes, C. F. L., Pereira, R. C., de Palmer Paixão Frugulhetti, I. C., \& Teixeira, V. L. (2007). In vitro antiviral effect of meroditerpenes isolated from the Brazilian seaweed Stypopodium zonale (Dictyotales). Planta Medica, 73, 1221-1224.

de Sousa, A. P. A., Torres, M. R., Pessoa, C., de Moraes, M. O., Filho, F. D. R., Alves, A. P. N. N., \& Costa-Lotufo, L. V. (2007). In vivo growth-inhibition of Sarcoma 180 tumor by alginates from brown seaweed Sargassum vulgare. Carbohydrate Polymers, 69, 7-13. de Souza, M. C. R., Marques, C. T., Dore, C. M. G., da Silva, F. R. F., Rocha, H. A. O., \& Leite, E. L. (2007). Antioxidant activities of sulfated polysaccharides from brown and red seaweeds. Journal of Applied Phycology, 19, 153-160.

Sugiura, Y., Matsuda, K., Yamada, Y., Nishikawa, M., Shioya, K., Katsuzaki, H., et al. (2007). Anti-Allergic phlorotannins from the edible brown alga, Eisenia Arborea. Food Science and Technology Research, 13, 54-60.

Targett, N. M., \& Arnold, T. M. (1998). Predicting the effects of brown algal phlorotannins on marine herbivores in tropical and temperate oceans. Journal of Phycology, 36, 195-205.

Venkateswarlu, S., Panchagnula, G. K., Gottumukkala, A. L., \& Subbaraju, G. V. (2007). Synthesis, structural revision, and biological activities of $4^{\prime}$-chloroaurone, a metabolite of marine brown alga Spatoglossum variabile. Tetrahedron, 63, 6909-6914.

Wang, Y., Han, F., Hu, B., Li, J. B., \& Yu, W. G. (2006). In vivo prebiotic properties of alginate oligosaccharides prepared through enzymatic hydrolysis of alginate. Nutrition Research, 26, 597-603.

Wang, R., Xiao, H., Wang, Y., Zhou, W., \& Tang, X. (2007). Effects of three macroalgae, Ulva linza (Chlorophyta), Corallina pilulifera (Rhodophyta) and Sargassum thunbergii (Phaeophyta) on the growth of the red tide microalga Prorocentrum donghaiense under laboratory conditions. Journal of Sea Research, 58, 189-197.

Wang, Y., Xu, Z., Bach, S., \& MacAllister, T. (2009). Sensitivity of Escherichia coli to seaweed (Ascophyllum nodosum) phlorotannins and terrestrial tannins. Asian-Australian Journal of Animal Science, 22, 238-245.

Wijesekara, I., Pangestuti, R., \& Kim, S. K. (2011). Biological activities and potential health benefits of sulfated polysaccharides derived from marine algae. Carbohydrate Polymers, 84, 14-21.

Xu, X., Song, F., Wang, S., Li, S., Xiao, F., Zhao, J., et al. (2004a). Dibenzyl bromophenols with diverse dimerization patterns from the brown alga Leathesia nana. Journal of Natural Products, 67, $1661-1666$.

Xu, X. L., Fan, X., Song, F. H., Zhao, J. L., Han, L. J., Yang, Y. C., et al. (2004b). Bromophenols from the brown alga Leathesia nana. Journal of Asian Natural Products Research, 6, 217-221.

Yang, H. C., Zeng, M. Y., Dong, S. Y., Liu, Z. Y., \& Li, R. (2010). Antiproliferative activity of phlorotannin extracts from brown algae Laminaria japonica Aresch. Chinese Journal of Oceanology and Limnology, 28, 122-130.

Yoon, S. J., Pyun, Y. R., Hwang, J. K., \& Mourão, P. A. S. (2007). A sulfated fucan from the brown alga Laminaria cichorioides has mainly heparin cofactor II-dependent anticoagulant activity. Carbohydrate Research, 342, 2326-2330.

Zhu, W., Ooi, V. E. C., Chan, P. K. S., \& Ang Jr., P. O. (2003). Inhibitory effect of extracts of marine algae from Hong Kong against Herpes simplex viruses. In A. R. O. Chapman, R. J. Anderson, V. J. Vreeland, \& I. R. Davison (Eds.), Proceedings of the 17th international seaweed symposium (pp. 159-164). Oxford: Oxford University Press.

Zhu, W., Chiu, M. C. L., Ooi, V. E. C., Chan, P. K. S., \& Angjr, O. P. (2004). Antiviral property and mode of action of a sulfated polysaccharide from Sargassum platens against herpes simplex virus type 2. International Journal of Antimicrobial Agents, 24, 18-25.

Zubia, M., Fabre, M. S., Kerjean, V., Lann, K. L., Stiger-Pouvreau, V., Fauchon, M., \& Deslandes, E. (2009). Antioxidant and antitumoural activities of some Phaeophyta from Brittany coasts. Food Chemistry, 116, 693-701. 